\title{
Satu Tinjauan Muzikologi Lagu Melayu Asli
}

\author{
Chamil Arkhasa Nikko Mazlan ${ }^{1}$, Mohd Hassan Abdullah², Suflan Faidzal Arshad ${ }^{3}$ \\ Mohd Khair Abdul Latif ${ }^{4}$, Ramlan Mohd Imam ${ }^{5}$, Isyam Swardy Daud \\ ${ }^{1,2,3}$ Universiti Pendidikan Sultan Idris, Malaysia \\ ${ }^{4,5,6}$ Akademi Seni Budaya dan Warisan Kebangsaan, Malaysia \\ 1emel: jazzerlogy@gmail.com
}

Diterbitkan dalam talian: 10 Disember 2020

Cite this article (APA): Mazlan, C. A. N., Abdullah, M. H., Arshad, S. F., Abdul Latif, M. K., Mohd Imam, R., \& Daud, I. S. (2020). Satu Tinjauan Muzikologi Lagu Melayu Asli. JuraiSembah, 1(2), 14-26. https://doi.org/10.37134/juraisembah.vol1.2.2.2020

\begin{abstract}
Abstrak
Kajian mengenai muzik tradisional semakin mendapat tempat dalam kalangan para sarjana, khususnya melibatkan salah satu muzik Malaysia, iaitu lagu Melayu Asli. Hasilnya, terdapat banyak artikel yang mengkaji lagu Melayu Asli, baik dari kaca mata instrumentalis mahupun dari sudut nyanyian vokal. Artikel ini melampirkan tinjauan dalam lagu Melayu Asli, berfokuskan pada ciri-ciri yang terkandung di dalamnya. Metodologi yang digunakan untuk meninjau ciri lagu Melayu Asli ini menggunakan analisis dokumen kualitatif dengan pendekatan analisis kandungan daripada artikel dan diskografi lagu Melayu Asli. Bagi meningkatkan kesahan dapatan yang diperolehi daripada artikel dan diskografi, triangulasi dilakukan dengan kaedah temu bual. Rumusannya, ciri-ciri umum lagu Melayu Asli boleh dilihat dari aspek berikut: struktur asal komposisi lagu Melayu Asli berasaskan struktur AB, kemudian ditambah dengan bahagian intro, interlud dan outro. Rentak asli atau senandung ini dimainkan dalam tempo yang perlahan, sekitar 55 sehingga 75 bit per minit. Akhir sekali, ciri yang harus ada dalam komposisi lagu Melayu Asli ialah melodi pengantar lagu, iaitu satu rangkai melodi pendek yang dimainkan sebelum atau selepas melodi utama atau melodi nyanyian. Ciri pengantar lagu ini juga seperti fungsi counter-melody yang melengkapi melodi utama dalam lagu Melayu Asli.
\end{abstract}

Kata kunci: analisis dokumen, lagu Melayu Asli, muzikologi, muzik tradisional Malaysia, pendidikan muzik

\begin{abstract}
In recent years, studies in traditional music have become popular amongst scholars, particularly of Malaysia's traditional music, Malay Asli song, known as lagu Melayu Asli. Hence this led the researchers to a piece of the vast information available regarding Malays Asli songs, either from the standpoint of the instrumentalist or in the context of singing techniques. This paper aims to generate a comprehensive description of the elements of music in Malay Asli Songs. To reorganise this information, the researchers conducted a literature review to examine the characteristic of a musical norm in Malay Asli song using qualitative document analysis as our methodology. All related documents such as articles and discography of the Malay Asli song were examined using content analysis technique. To triangulate the data, a semi-structured interview was done. An overview of the main elements of Malay Asli song is provided, discussed in the aspects of rhythm, meter, tempo, timbre, harmony and melodies. To conclude our discussion, most dominant elements in any Malay Asli song can be seen from the following aspects: Malay Asli song musical structure is based on $\mathrm{AB}$ form, then added with the intro, interlude and outro. Malay Asli song being played in a slow tempo, around 55 to 75 beats per minute. This slow tempo known as asli or senandung. Finally, a must have feature that should be present in the composition of Malay Asli song, pengantar lagu, a short counter-melody lines, being played before or after the main melodies. Furthermore, in the final section, we offering some recommendations for future research.
\end{abstract}

Keywords: Malay Asli song, Malaysian traditional music, music education, musicology, systematic review 


\section{Pengenalan}

Muzik tradisional kini semakin mendapat tempat dalam kalangan pemuzik dan pencinta budaya. Tidak hanya dalam persembahan, para cendekiawan juga memperlihatkan minat dalam mengkaji muzik tradisional. Di Malaysia juga tidak terkecuali, yang mana terdapat peningkatan dalam kalangan penyelidik yang memfokus kepada muzik tradisional Melayu Asli seperti Bahasuan (2003), Rizaldi (2010), Hashim (2012), Silahudin (2010 \& 2013), Za'Ba et al. (2011), Abu Bakar (2014), Arshad (2015), Ahmed dan Kechot (2015), Karim (2016), Ritawati (2017), Matusky dan Tan (2017), Isyak (2018), Mohd Rosly (2018), Alimi dan Kassin (2018), Ayderova et al. (2020) serta Mazlan dan Abdullah (2020).

Berdasarkan kajian lepas, muzik Malaysia dibahagikan kepada tiga kategori iaitu muzik popular dan kontemporari, muzik klasik, muzik rakyat dan muzik sinkretik (Matusky \& Tan, 2017). Dalam artikel ini, penulis memfokus kepada kategori muzik sinkretik, iaitu lagu Melayu Asli. Menariknya, lagu Melayu Asli ini bukan sahaja berada dalam kategori muzik rakyat mahupun muzik klasik, tetapi dalam kategori muzik sinkretik (Matusky, 1985; Za'Ba et al., 2011; Hashim, 2012; Pillai, 2013; Abu Bakar, 2014; Irving; 2014; Arshad, 2015; Ahmed \& Kechot, 2015; Matusky \& Tan, 2017; Mohd Rosly, 2018). Selain daripada lagu Melayu Asli, kategori muzik sinkretik juga meliputi muzik zapin, inang, joget, ghazal, dondang sayang, boria, keroncong dan bangsawan (Matusky \& Tan, 2017).

Artikel ini membincangkan lagu Melayu Asli dari sudut muzikologi, kerana daripada penelitian mendapati genre muzik ini perlu diketengahkan dalam membincangkan ciri-ciri yang terdapat dalam muzik tradisional Melayu ini. Lagu Melayu Asli juga sering menjadi medium dalam memperkenalkan salah satu daripada khazanah dalam muzik tradisional Melayu. Sebagaimana yang dinyatakan Datuk Norliza Rofli, Ketua Pengarah Jabatan Kebudayaan dan Kesenian Negara (JKKN) dalam Abdullah (2015) dan BERNAMA (2015), jika rakyat di Itali mengangkat muzik opera dan klasikal mereka, lagu Melayu Asli juga sepatutnya dilihat sebagai khazanah yang menjadi kebanggaan kita sebagai rakyat Malaysia. Biduan Negara, allahyarham Tan Sri S. M. Salim juga pernah menyuarakan, usaha dalam memelihara lagu Melayu Asli ini perlu diperbanyakkan, kerana kekurangan bahan untuk generasi baru dalam pengetahuan nyanyian lagu Melayu Asli (Astro Awani, 2013). Walaupun apa yang disampaikan oleh Allahyarham Tan Sri S. M. Salim ini dalam konteks nyanyian lagu Melayu Asli, namun isi tersirat yang jelas kelihatan daripada hujah beliau ini secara tidak langsung merujuk pada kekurangan bahan rujukan. Pendapat yang sama ini juga dikongsi dalam kalangan pengkaji lagu Melayu Asli terdahulu seperti Abu Bakar (2014), Arshad (2015), Mohd Rosly (2018) dan Isyak (2018). Faktor kekurangan bahan ini wujud kerana pembelajaran muzik tradisional selalunya dipelajari melalui tradisi lisan (Mohd Shah, 2013; Abu Bakar, 2014; Arshad, 2015; Mohd Shah \& Masumi, 2016; Isyak, 2018; Mohd Rosly, 2018; Ayderova et al., 2020).

Melalui tradisi lisan, pengajaran dan pembelajaran (PdP) dilakukan dengan demonstrasi. Contohnya seperti yang diterangkan Arshad (2015), guru menunjukkan kemahiran tertentu dan murid meniru semula apa yang dilihat, tanpa berpandukan bahan pengajaran yang dijadikan panduan dalam mempelajari lagu Melayu Asli. Panduan dalam PdP itu semua berdasarkan kemahiran dan pengalaman individual guru yang mengajar, iaitu dalam kalangan pemuzik mahupun penyanyi lagu Melayu Asli (Arshad, 2015; Ritawati, 2017; Isyak, 2018; Mohd Rosly, 2018). Rentetan itu, wujud pelbagai definisi dalam penyampaian lagu Melayu Asli, kerana setiap tenaga pakar yang mengajar punyai pengalaman dan pengetahuan yang berbeza-beza dalam menyampaikan ilmu pengetahuan lagu Melayu Asli (Arshad, 2015; Ritawati, 2017; Isyak, 2018; Mohd Rosly, 2018). Daripada kepelbagaian yang wujud ini, penulis terdorong untuk meneroka ciri-ciri lagu Melayu Asli berdasarkan kajian-kajian lepas.

\section{Metodologi}

Penelitan sistematik dalam penulisan ini menggunakan metodologi analisis kandungan kualitatif, yang diperoleh daripada artikel-artikel dan diskografi lagu Melayu Asli. Untuk meningkatkan kesahan data yang ditemukan daripada sumber yang pelbagai, kaedah triangulasi digunakan (Creswell, 2016; Creswell \& Creswell, 2018; Creswell \& Poth, 2018). Kaedah triangulasi dilakukan dengan proses temu bual pakar, bertujuan untuk mengesahkan dapatan mengenai ciri-ciri lagu Melayu Asli yang ditemui dalam dokumen berbentuk artikel dan diskografi lagu Melayu Asli. Analisis kandungan dalam penulisan ini berfokuskan pada ciri-ciri yang terdapat dalam lagu Melayu Asli iaitu masa, nada dan gabungan keduanya (SchmidtJones, 2012).

Artikel-artikel yang berfokuskan lagu Melayu Asli diakses secara dalam talian melalui pangkalan data Google dan Googe Scholar. Diskografi yang digunakan dalam pula diakses melalui pangkalan 
YouTube. Dengan dunia yang serba moden, pencarian bahan secara dalam talian ini bukan saja mudah, hanya di hujung jari, malahan beribu jurnal, kertas persidangan dan sumber lain daripada pelbagai bidang pengajian disajikan (Creswell, 2013). Orduña-Malea et al. (2014) juga bersependapat dan menyatakan pangkalan data Google Scholar ini merupakan satu revolusi perkhidmatan web yang tidak terhad pada data perpustakaan atau bibligrafi sahaja.

\section{Perbincangan}

\section{Elemen Masa (Tempo, Meter dan Irama)}

Bila muzik berkumandang, kita dapat merasakan sama ada muzik yang dialunkan itu perlahan mahupun cepat. Dalam konteks muzik sinkretik Malaysia, iaitu lagu Melayu Asli, rentak yang dimainkan dikenali sebagai asli atau rentak senandung yang merujuk pada gaya persembahan dengan tempo yang perlahan dan melankolik (Bahasuan, 2003; Manoharan et al., 2009; Rizaldi, 2010; Arshad, 2015; Mohd Rosly, 2018). Menurut seorang seniman muzik dan sastera Riau, Zuarman Ahmad, menyatakan rentak asli ini dikenali sebagai rentak senandung di Indonesia (temu bual peribadi, Mac 14, 2016). Penerangan rentak asli atau senandung ini berkait dengan bahagian tempo yang diterangkan di bawah.

Dalam konteks muzik, tempo merujuk pada kelajuan bit per minit yang dimainkan (Dewan Bahasa \& Pustaka, n.d.; Schmidt-Jones, 2012). Jadual 1 menunjukkan tempo lagu Melayu Asli berdasarkan kajian lepas:

Jadual 1: Tempo Lagu Melayu Asli

\begin{tabular}{cc}
\hline Tempo & Kajian \\
\hline 55 sehingga 58 bit per minit & Silahudin (2010) \\
55 bit per minit & Isyak (2018) \\
60 bit per minit & Rizaldi (2010), Za'Ba et al. (2011) \\
65 sehingga 75 bit per minit & Arshad (2015) \\
62 bit per minit & Mrcupan (2009) \\
60 bit per minit & SuriaRecordsSRC (2013) \\
55 bit per minit & Santai Minda (2012) \\
\hline
\end{tabular}

Jadual 1 menunjukkan tempo yang digunakan dalam lagu Melayu Asli. Terdapat persamaan tempo antara Rizaldi (2010), Za'Ba et al., (2011) dan SuriaRecordsSRC (2013), iaitu sekitar 60 bit per minit. Untuk tempo 55 bit per minit, terdapat tiga kajian yang mengongsi pendapat yang sama, Silahudin (2010), Santai Minda (2012) dan Isyak (2018). Namun Silahudin (2010) menambah tempo dalam lagu Melayu Asli sehingga 58 bit per minit. Hasil daripada transkripsi diskografi lagu Melayu asli bertajuk Damak nyanyian oleh Allahyarham Sudirman pula, memberikan kiraan tempo yang berbeza, iaitu sekitar 62 bit per minit (Mrcupan, 2009). Akhir sekali, Arshad (2015) menyatakan bahawa tempo yang digunakan dalam lagu Melayu Asli ialah sekitar 65 sehingga 75 bit per minit.

Seterusnya bahagian ini membincangkan meter, merujuk pada jumlah not yang terdapat dalam sesebuah baris muzik. Dalam skor muzik, meter dilabelkan sebagai tanda masa (The Editors of Encyclopaedia Britannica, 2013). Kebanyakan kajian-kajian lepas menyimpulkan bahawa lagu Melayu Asli menggunakan meter 4/4 atau rentak empat sebagaimana yang dinyatakan oleh Bahasuan (2003), Mrcupan (2009), Manoharan et al. (2009), Rizaldi (2010), Mohd Nasir (2010), Santai Minda (2012), SuriaRecordsSRC (2013), Ahmed dan Kechot (2015), Arshad (2015), Isyak (2018) serta Mohd Rosly (2018).

Namun begitu, apa yang menarik, pengiraan yang digunakan oleh seorang pemain rebana menggunakan kiraan 8 bit, iaitu bersamaan dengan 8/4. Syamsul Zin, penolong konduktor dalam Orkestra Tradisional Malaysia (OTM), berkongsi pendapat beliau dengan menyatakan, frasa sebenar rentak asli ini dimain menggunakan meter 8/4 (Ahmed \& Kechot, 2015). Kenyataan ini juga disokong Zuarman Ahmad (temu bual peribadi, Mac 14, 2016) dan Pengarah Pusat Kebudayaan Universiti Sains Islam Malaysia, Ismail Ahmed (temu bual peribadi, April 30, 2020). Penggunaan 8 bit ini sebenarnya juga digunakan dalam tarian, kerana penari tidak merujuk pada skor muzik, tetapi mereka akan mencari nadi (pulse) dalam muzik itu sebagai panduan (Peter, 2019). Peter juga menjelaskan bahawa sebab kenapa pengiraan 4/4 menjadi 8/4 ialah kerana frasa muzikal selalunya terdiri daripada 2 atau 4 baris. Rentak asli yang dimainkan dalam 
persembahan muzik, secara tidak langsung merujuk pada rentak asli yang sama seperti yang digunakan tarian asli (Manoharan et al., 2009). Manoharan et al. turut menyatakan bahawa tarian asli ini diiringi dengan tempo yang perlahan, semiotik pada ciri-ciri puteri diraja yang ayu dan sopan (2009). Namun apa yang hendak dibahaskan dalam penulisan ini bukan mengenai tarian, tetapi dari aspek muziknya. Meter 8/4 tidak digunakan kerana tidak praktikal dan sukar untuk memuatkan 8 bit not krochet dalam satu baris, sebab itu digantikan dengan meter 4/4 (Nicksword87, 2014). Sebab itu ditukarkan pada meter 4/4, bertujuan untuk memudahkan pembacaan dan penulisan dalam skor muzik (Tim, 2020). Walaupun kedua meter 4/4 dan 8/4 ini berbeza dari segi istilah, akan tetapi kedua-duanya membawa maksud yang sama (Jazz_rock_feel, 2014; Nicksword87, 2014; Azrael667). Tanda masa atau meter ini hanya sebagai panduan untuk kita memahami apa yang komposer ingin lakukan, apa yang penting sesebuah lagu itu dimainkan seperti yang sepatutnya dimainkan (Azrael667, 2014). Berikut adalah contoh-contoh rentak asas senandung atau asli yang digunakan dalam dalam lagu Melayu Asli:

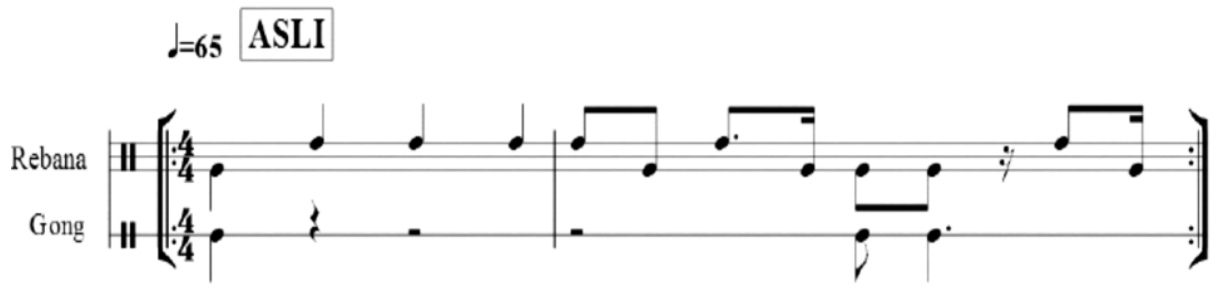

Rajah 1: Rentak senandung lagu Melayu Asli (Arshad, 2015, p. 55)

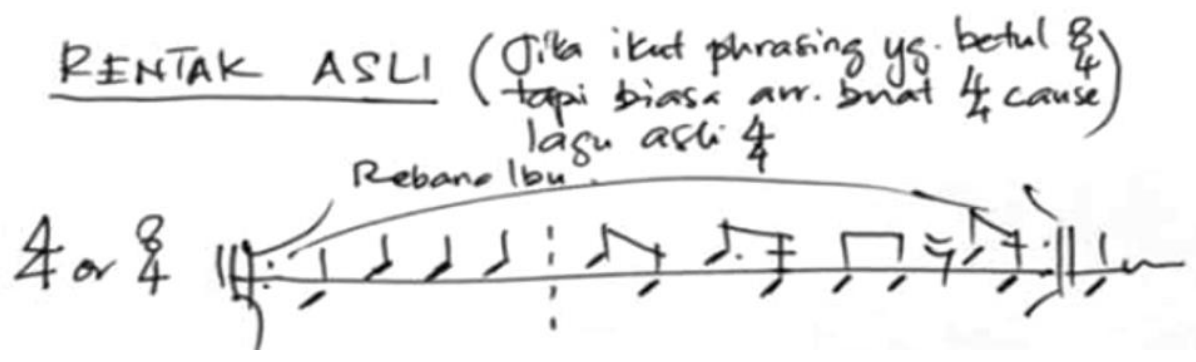

Rajah 2: Rentak senandung lagu Melayu Asli (Shamsul Zin dalam Ahmed \& Kechot, 2015, p. 315)

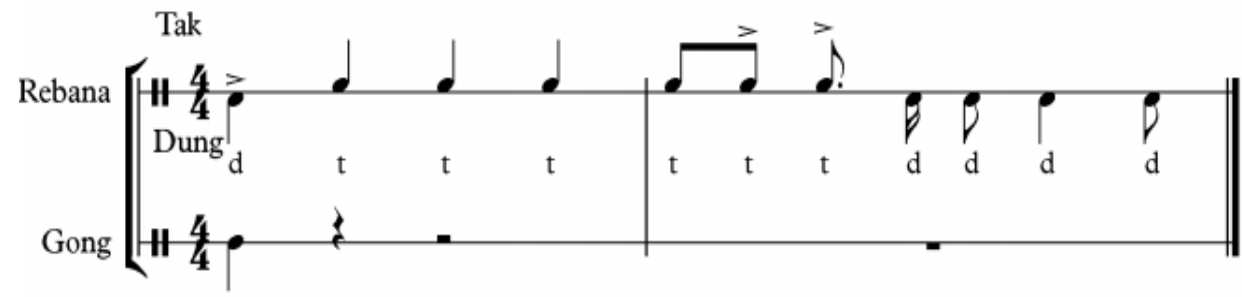

Rajah 3: Rentak senandung lagu Melayu Asli (Mohd Rosly, 2018, p. 26)

\section{Elemen Nada}

Timbre atau istilah lainnya dikenali sebagai ton, merujuk pada perbezaan bunyi (Berklee Online, 2018). Dalam konteks muzik, ton ini diibaratkan sebagai warna dalam mengenal pasti bunyi yang dihasilkan sama ada daripada vokal suara mahupun secara instrumental (Wright, 2016). Perbezaan timbre dalam lagu Melayu Asli boleh dilihat dari sudut penggunaan alat muzik dalam ensemble tersebut. Dalam ensembel lagu Melayu Asli, terdapat dua kategori timbre kategori yang boleh didapati, iaitu daripada kategori alat muzik utama yang terdiri daripada biola, akordian, rebana dan gong (Bahasuan, 2003; Abu Bakar, 2014; Arshad, 2015) dan kategori alat muzik iringan yang terdiri daripada alat muzik gitar akustik, serunai atau flut (Ahmed \& Kechot, 2015; Arshad, 2015) dan juga gitar bes (Arshad, 2015).

Beralih pada ciri-ciri harmoni yang terdapat dalam lagu Melayu Asli. Secara umumnya, harmoni merujuk pada kord. Terhasilnya kord ini apabila dua not dimainkan serentak (Kostka et al., 2012). Jika tiga 
not disusun secara vertikal dan dimainkan serentak, ia menghasilkan satu kord triad (Feezell, 2011; Kostka et al., 2012; Mazlan, 2016; Pilhofer \& Day, 2019). Kebanyakan harmoni yang digunakan dalam lagu Melayu Asli berteraskan kord triad (Zuarman Ahmad, temu bual peribadi, Mac 14, 2016; Mohd Khair Abdul Latif, temu bual peribadi, Febuari 26, 2019; Ramlan Mohd Imam, temu bual peribadi, Febuari 18, 2019).

Selain daripada kord triad (1-3-5), terdapat juga penggunakan kord tujuh iaitu seventh chord (1-35-7). Tetapi, kebanyakan kord tujuh yang digunakan dalam lagu Melayu Asli, merupakan kord tujuh yang berfungsi sebagai kord dominan tujuh (dominant seventh chord). Mohd Rosly (2018) ada menyatakan, perubahan harmoni ini boleh berlaku bila pemuzik Melayu Asli mendapat pendedahan dengan sistem tonal muzik barat. Oleh sebab itu, kita dapat melihat penggunaan kord tujuh yang diterangkan pada Rajah 4 dan Rajah 5 di bawah. Sistem tonal ini merujuk pada sistem atau susunan kord yang terdapat dalam skel yang sama, dikenali sebagai kord skel diatonik (Kostka et al., 2012). Bagi lebih memahami penggunaan kord tujuh ini, penulis melampirkan notasi di bawah:

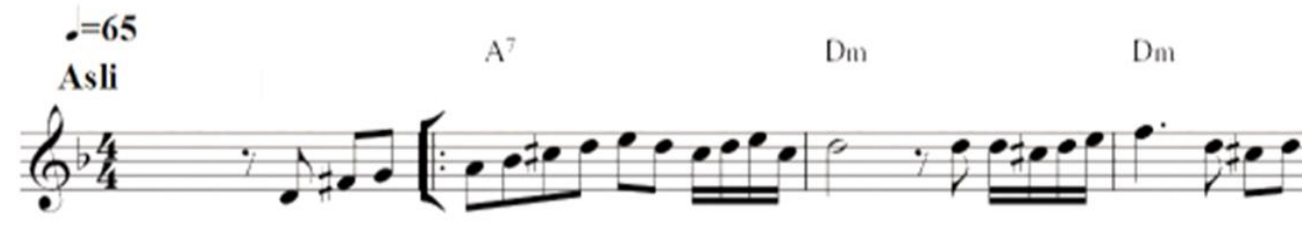

Rajah 4: Keratan melodi lagu Makan Sireh (Arshad, 2015, p. 70)

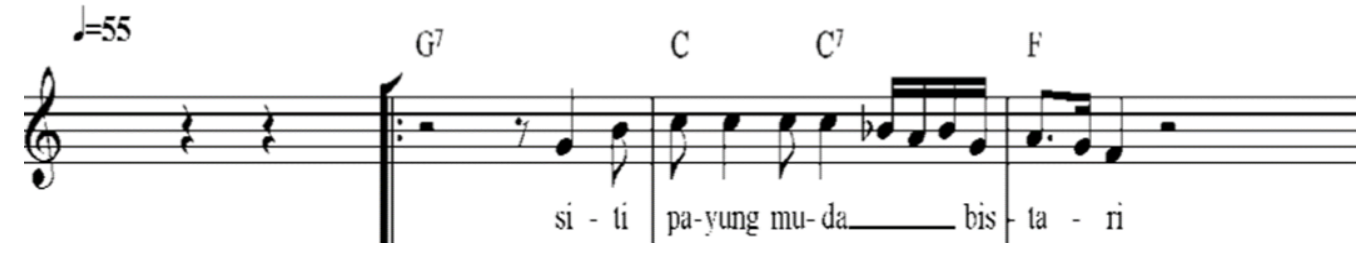

Rajah 5: Keratan melodi lagu Siti Payung (Isyak, 2018, p. 84)

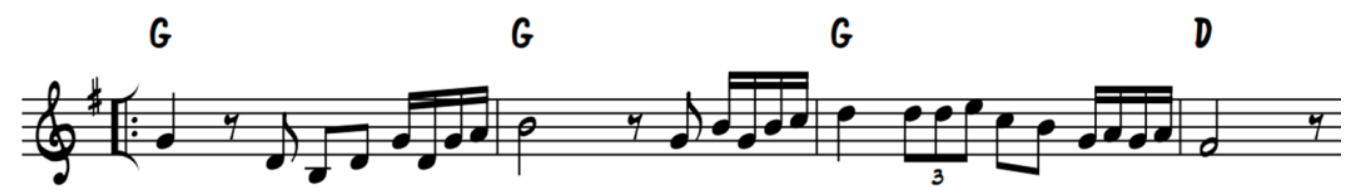

Rajah 6: Keratan lagu Damak Instrumental (Santai Minda, 2012)

Berdasarkan Rajah 4 dan Rajah 5, kedua contoh keratan ini diperolehi daripada kajian lepas Arshad (2015) dan Fadril Nidzam (2018), yang mana kord tujuh yang digunakan ini berfungsi sebagai kord dominan tujuh, iaitu kord dalam fungsi kaden $\mathrm{V}^{7}$-I. Jika dirujuk pada Rajah 4 , kord $\mathrm{A}^{7}$ itu merupakan kord kelima dari skel D minor, menjadikan ia sebagai kaden $\mathrm{V}^{7}$-I minor.

Merujuk pada Rajah 5 pula, kord $\mathrm{G}^{7}$ itu boleh dianggap sebagai kord kelima dari skel $\mathrm{C}$ major dalam kaden V-I. Kord $\mathrm{C}^{7}$ itu merujuk pada kord kelima dalam skel $\mathrm{F}$ major, juga merupakan kaden V-I. Tetapi, kord $\mathrm{C}^{7}$ ini berbeza sedikit fungsinya berbanding kord $\mathrm{G}^{7}$. Perbezaannya dari segi analisis muzikologinya, iaitu kord $\mathrm{C}^{7}$ dilabelkan sebagai V7/IV atau dikenali sebagai secondary dominant. $\mathrm{Kord} \mathrm{G}^{7}$ dilabel sebagai V7/I. Kord $\mathrm{A}^{7}$ pada dalam Rajah 4 juga merupakan secondary dominant, ini kerana kord diatonik asal dalam skel F major, adalah kord Amin, iaitu dilabel sebagai III ${ }^{\mathrm{min}}$. Kord $\mathrm{A}^{7}$ ini dipinjam kerana kord seterusnya Dmin. Justikasi kenapa kord $\mathrm{A}^{\mathrm{min}}$ boleh menjadi kord $\mathrm{A}^{7}$, disebabkan dalam melodi lagu pada baris kedua Rajah 4 ini mempunyai not $\mathrm{C}^{\#}$ pada bit kedua. Not $\mathrm{C} \#$ ini merupakan not major ketiga (major third) untuk kord $\mathrm{A}^{7}$.

Persamaan antara kord $\mathrm{A}^{7}$ dalam Rajah 4, kord $\mathrm{G}^{7}$ dan $\mathrm{C}^{7}$ dalam Rajah 5, ketiga-tiga kord ini boleh dilabel sebagai kord dominan yang berfungsi sebagai primary dominant, iaitu kord tunggal dominan tujuh yang memang wujud dalam skel diatonik major mahupun minor. Kord $\mathrm{G}^{7}$ boleh dilabel sebagai $\mathrm{V}^{7}$ jika kita 
kaitkan dalam skel $\mathrm{C}$ major. Begitu juga dengan kord $\mathrm{C}^{7}$ sebagai $\mathrm{V}^{7}$ dalam skel $\mathrm{F}$ major. kord $\mathrm{A}^{7}$, dilabel $\mathrm{V}^{7}$ tetapi dalam skel $\mathrm{D}$ major.

Jika diperhatikan pada Rajah 6, hasil daripada transkripsi diskografi lagu Damak secara instrumental (Santai Minda, 2012), kord yang dimainkan hanya dalam bentuk triad. Ini adalah kerana dalam proses menganalisis transkripsi seperti yang dilampirkan dalam contoh Rajah 6, penulis menggunakan kaedah kord skel diatonik dalam triad dari not-not dalam skel G, iaitu $\mathrm{G}^{\text {maj }}\left(\mathrm{I}^{\mathrm{maj}}\right)$, Amin $\left(\mathrm{II}^{\mathrm{min}}\right), \mathrm{B}^{\mathrm{min}}\left(\mathrm{III}^{\mathrm{min}}\right)$, $\mathrm{C}^{\text {maj }}\left(\mathrm{IV}^{\text {maj }}\right), \mathrm{D}^{\text {maj }}\left(\mathrm{V}^{\mathrm{maj}}\right), \mathrm{E}^{\mathrm{min}}\left(\mathrm{VI}^{\mathrm{min}}\right)$ dan $\mathrm{F}^{\# \text { dim }}\left(\mathrm{VII}^{\mathrm{dim}}\right)$. Sebab itu kord D dalam baris keempat dalam Rajah 6 dilabel sebagai kord D sahaja. Kord D major ini boleh bertukar menjadi kord $\mathrm{D}^{7}$ jika penulis menggunakan diatonik kord tujuh iaitu, $\mathrm{G}^{\text {maj7 }}\left(\mathrm{I}^{\mathrm{maj}}\right), \mathrm{A}^{\mathrm{min} 7}\left(\mathrm{II}^{\mathrm{min}}\right), \mathrm{B}^{\mathrm{min} 7}\left(\mathrm{III}^{\mathrm{min}}\right), \mathrm{C}^{\text {maj7 }}\left(\mathrm{IV}^{\mathrm{maj}}\right), \mathrm{D}^{7}\left(\mathrm{~V}^{7}\right), \mathrm{E}^{\mathrm{min} 7}\left(\mathrm{VI}^{\mathrm{min}}\right)$ dan $\mathrm{F}^{\# \min 765}\left(\mathrm{VII}^{\mathrm{dim}}\right)$.

Not kelima (V) dan ketujuh (VII) itu, jika berpandukan kord skel diatonik triad, dilabel sebagai $\mathrm{D}^{\text {maj }}$ dan $\mathrm{F}^{\# \mathrm{dim}}$. Kedua kord ini boleh bertukar kualiti bila kita menggunakan kord diatonik tujuh, menjadi kord $\mathrm{D}^{7}\left(\mathrm{~V}^{7}\right)$ dan $\mathrm{F}^{\# \min 765}\left(\mathrm{VII}^{\mathrm{min} 7 b 5}\right)$. Ini berlaku kerana penambahan satu not, iaitu not ketujuh dari kord Dmaj yang terdiri dari not $\mathrm{D}, \mathrm{F}^{\#}$, A (1-3-5) menjadi $\mathrm{D}^{7}$ kerana tonaliti kord mengandungi not $\mathrm{D}, \mathrm{F}^{\#}$, A dan $\mathrm{C}$ (13-5-b7). Begitu juga dengan kord $\mathrm{F}^{\# \mathrm{dim}}$ yang terdiri dengan not F\#, A, C (1-b3-b5), bertukar menjadi $\mathrm{F}^{\# \min 7 b 5}$ kerana ditambah dengan satu not $\mathrm{E}$, kord yang asalnya berkualiti diminished, menjadi half diminished atau min7b5 kerana kord terdiri dari not F\#, A, C dan E (1-b3-b5-b7). Pengolahan kord sama ada menggunakan kord triad mahupun kord tujuh ini boleh digunakan selagi ia tidak menganggu melodi. Perbezaan yang wujud dalam kord yang digunakan itu hanya berbeza dari segi warna suara atau harmoni, dalam erti kata lain merujuk pada timbre dalam sesebuah lagu (Wright, 2016).

Seterusnya, elemen melodi lagu Melayu Asli mempunyai pelbagai interpretasi, terutama dalam penghuraian yang diperolehi daripada pengkaji-pengkaji lepas. Sebelum penerangan lebih lanjut, elemen melodi yang diterangkan dalam bahagian ini merujuk pada frasa melodi lagu, satu struktur yang harus ada dalam komposisi lagu Melayu Asli. Melodi ini bukan merujuk pada melodi utama, tetapi melodi yang dikenali sebagai frasa melodi (Abu Bakar, 2014; Arshad, 2015).

Abu Bakar (2014) dalam kajian beliau, menyatakan bahawa terdapat enam frasa melodi. Dapatan kajian beliau diperoleh melalui kaedah temu bual bersama empat orang informan, dua daripadanya merupakan pensyarah muzik dan dua orang lagi penyanyi yang berpengalaman dalam nyanyian tradisional. Selain daripada itu, analisis dokumen juga digunakan, iaitu video rakaman seniman muzik tradisional Malaysia, Allahyarham Rahim Jantan. Berikut merupakan enam frasa yang dicadangkan oleh Abu Bakar (2014):

1) Buka lagu

2) Melodi pengantar

3) Frasa ulang bahagian pembayang

4) Frasa penghubung

5) Frasa ulang bahagian maksud

6) Frasa penamat

Hasil daripada kajian lepas Arshad (2015), yang mana dapatan juga diperoleh melalui kaedah temu bual bersama lima orang tokoh dalam lagu Melayu Asli, perhatian turut serta dan analisis dokumen. Beliau merumuskan bahawa terdapat empat frasa melodi penting dalam lagu Melayu Asli iaitu:

1) Buka lagu

2) Pengantar lagu

3) Sendi lagu

4) Pemati lagu 
Bagi memahami perbezaan antara kenyataan Abu Bakar (2014) dan Arshad (2015), penulis menyenaraikan pengertian frasa melodi para pengkaji ini dalam matrik di bawah:

Jadual 2: Perbezaan Frasa Melodi

\begin{tabular}{|c|c|c|c|}
\hline \multicolumn{2}{|c|}{ Abu Bakar (2014) } & \multicolumn{2}{|l|}{ Arshad (2015) } \\
\hline $\begin{array}{l}\text { Bahagian } \\
\text { Buka Lagu / } \\
\text { Intro }\end{array}$ & $\begin{array}{l}\text { Frasa yang dicipta khusus dengan } \\
\text { berpandukan tangga nada lagu yang } \\
\text { dipersembahkan. Seorang penyanyi } \\
\text { perlu menghafal bahagian ini agar } \\
\text { mudah untuk mengetahui bila perlu } \\
\text { mula menyanyi melodi dan membantu } \\
\text { meningkatkan keyakinan bila menyanyi } \\
\text { di hadapan penonton. }\end{array}$ & $\begin{array}{l}\text { Setiap lagu Melayu Asli terdiri } \\
\text { dengan buka lagu yang tersendiri, } \\
\text { yang mana melodi buka lagu ini } \\
\text { berhubung kait dengan melodi } \\
\text { nyanyian. }\end{array}$ & $\begin{array}{l}\text { Buka Lagu / } \\
\text { Intro }\end{array}$ \\
\hline $\begin{array}{l}\text { Melodi } \\
\text { Pengantar / } \\
\text { Kaden Pintu }\end{array}$ & $\begin{array}{l}\text { Sebuah melodi yang dimainkan selepas } \\
\text { bahagian buka lagu dan sebelum vokal } \\
\text { mula menyanyi. Frasa melodi ini juga } \\
\text { dikenali sebagai forephrase. }\end{array}$ & $\begin{array}{l}\text { Dikenali sebagai forephrase, } \\
\text { merujuk pada rangkaian melodi } \\
\text { yang mempunyai not-not yang } \\
\text { tertentu dari skel atau modes. } \\
\text { Dimainkan sebagai penghubung } \\
\text { lirik dengan baris pertama } \\
\text { pembayang atau maksud pantun. }\end{array}$ & $\begin{array}{l}\text { Pengantar } \\
\text { Lagu }\end{array}$ \\
\hline $\begin{array}{l}\text { Frasa Ulang } \\
\text { Bahagian } \\
\text { Pembayang }\end{array}$ & $\begin{array}{l}\text { Mengandungi dua bahagian melodi } \\
\text { yang direka secara improvisasi, sebagai } \\
\text { penanda untuk penyanyi untuk } \\
\text { mengulangi lirik bahagian pembayang } \\
\text { pantun. }\end{array}$ & $\begin{array}{lrr}\text { Melodi } & \text { penghubung } & \text { yang } \\
\text { dimainkan } & \text { selepas } & \text { penyanyi } \\
\text { mengulangi } & \text { bahagian } & \text { baris } \\
\text { pembayang } & \text { pantun, } & \text { sebelum } \\
\text { menyanyi menyanyikan } & \text { bahagian } \\
\text { maksud pantun. } & \end{array}$ & Sendi Lagu \\
\hline $\begin{array}{l}\text { Frasa } \\
\text { Penghubung / } \\
\text { Bridge }\end{array}$ & $\begin{array}{l}\text { Bahagian penghubung antara bahagian } \\
\text { A iaitu bahagian lirik pembayang } \\
\text { pantun dengan bahagian B yang } \\
\text { merujuk pada bahagian lirik maksud } \\
\text { pantun. }\end{array}$ & $\begin{array}{l}\text { Bahagian yang menjadi penanda } \\
\text { aras untuk menamatkan sesebuah } \\
\text { lagu, dalam konteks lagu Melayu } \\
\text { Asli, penamat lagu adalah selepas } \\
\text { penyanyi selepas menyanyikan } 4 \\
\text { baris seni kata pembayang dan } \\
\text { maksud pantun. }\end{array}$ & $\begin{array}{l}\text { Pemati Lagu } \\
\text { / Penamat } \\
\text { Lagu }\end{array}$ \\
\hline $\begin{array}{l}\text { Frasa Ulang } \\
\text { Bahagian } \\
\text { Maksud }\end{array}$ & $\begin{array}{l}\text { Disusunkan dengan gaya yang } \\
\text { melismatik dengan penggunaan } \\
\text { ornamen atau bunga lagu. Dikatakan } \\
\text { pemuzik yang mengiringi memerlukan } \\
\text { kemahiran yang tinggi untuk } \\
\text { menghasilkan gaya melodi pada } \\
\text { bahagian ini. }\end{array}$ & & \\
\hline Frasa Penutup & $\begin{array}{l}\text { Bahagian penutup ini selalunya } \\
\text { digayakan dengan gaya 'ritard', } \\
\text { perlahan secara beransuran. Namun, } \\
\text { bahagian ini tidak begitu jelas. }\end{array}$ & & \\
\hline
\end{tabular}

Berdasarkan Jadual 2, melalui interpretasi terhadap kedua penulis di atas, tidak banyak perbezaan dalam penghuraian frasa melodi antara kedua penyelidik ini. Apa yang perlu jelas ialah kajian Abu Bakar (2014) berfokuskan konteks lagu Melayu Asli dalam kontekstual nyanyian vokal, manakala Arshad (2015) pula melalui kontekstual seorang instrumentalis.

Namun apa yang ingin penulis ketengahkan dalam artikel ini berfokuskan pada frasa melodi yang diistilahkan sebagai pengantar lagu. Walaupun pengantar lagu boleh dikenali dalam istilah yang pelbagai, seperti muzik pengantar (Abu Bakar, 2014; Ahmed \& Kechot, 2015) dan pengantar lagu (Rizaldi, 2010; Arshad, 2015), namun apa yang penting untuk diketahui ialah fungsi sebenar pengantar lagu. Dari 
kontekstual nyanyian vokal, pengantar lagu ini berfungsi sebagai panduan untuk penyanyi memulakan nyanyian (Abu Bakar, 2014; Arshad, 2015, Ahmed \& Kechot, 2015; Zuarman Ahmad, temu bual peribadi, Mac 14, 2016; Isyak; 2018). Dari kontekstual instrumental pula, pengantar lagu merupakan ciri yang sangat penting dalam komposisi lagu Melayu Asli (Zuarman Ahmad, temu bual peribadi, Mac 14, 2016), kerana frasa pengantar lagu ini merupakan satu bahagian melodi yang sebati dengan melodi utama yang dimainkan secara instrumental atau melalui nyanyian vokal (Rizaldi, 2010). Sebab itulah pengantar lagu ini dilihat sebagai satu frasa melodi yang melengkapkan melodi lagu Melayu Asli (Arshad, 2015; Zuarman Ahmad, temu bual peribadi, Mac 14, 2016; Ismail Ahmed, temu bual peribadi, April 30, 2020). Sebab itu juga pengantar lagu disifatkan sebagai keunikan dalam lagu Melayu Asli (Rizaldi, 2010; Abu Bakar, 2014; Arshad, 2015; Ahmed \& Kechot, 2015; Zuarman Ahmad, temu bual peribadi, Mac 14, 2016; Isyak, 2018; Ismail Ahmed, temu bual peribadi, April 30, 2020). Berikut ialah contoh pengantar lagu yang terdapat dalam komposisi lagu Melayu Asli:

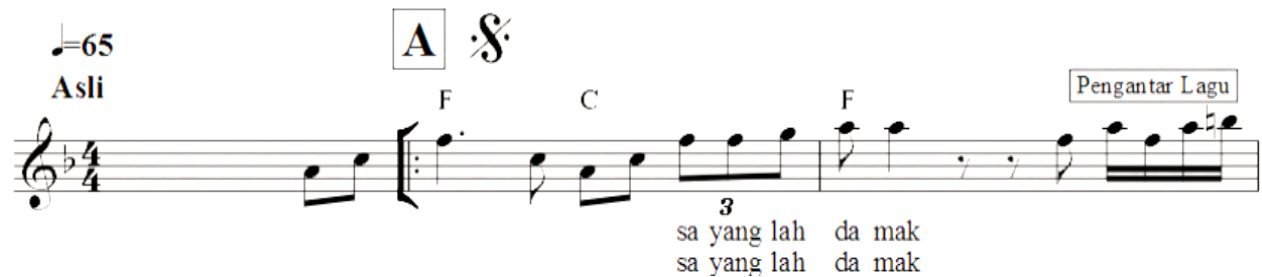

Rajah 7: Melodi pengantar pada lagu Melayu Asli bertajuk Damak (Arshad, 2015, p. 72)

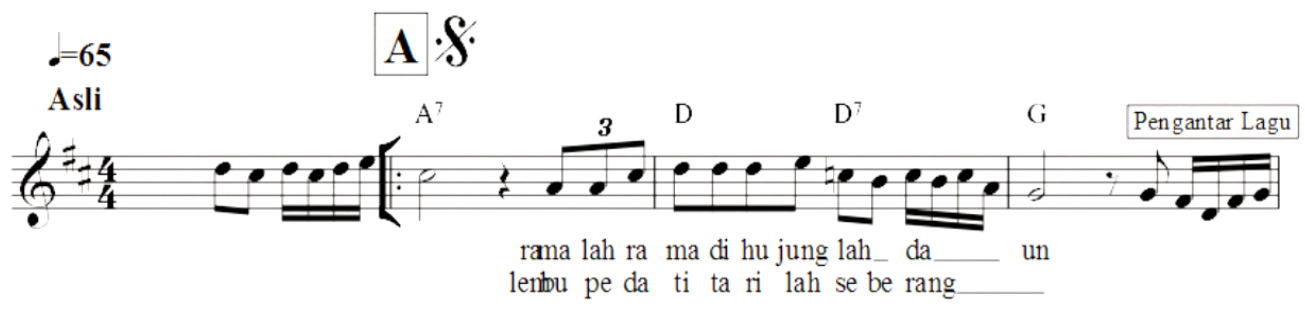

Rajah 8: Melodi pengantar pada lagu Melayu Asli bertajuk Siti Payung (Arshad, p. 74)

Untuk memahami pengantar lagu dengan lebih eksplisit, penulis melampirkan contoh pengantar lagu dalam Rajah 9 dan Rajah 10:

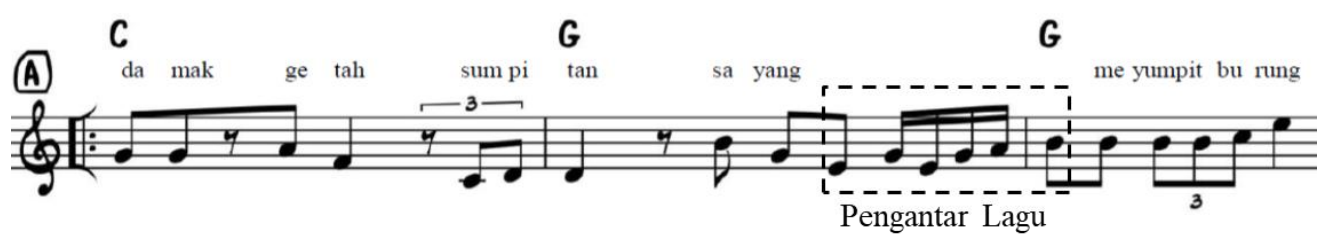

Rajah 9: Melodi pengantar dari lagu Damak nyanyian Sudirman (Mrcupan, 2009)

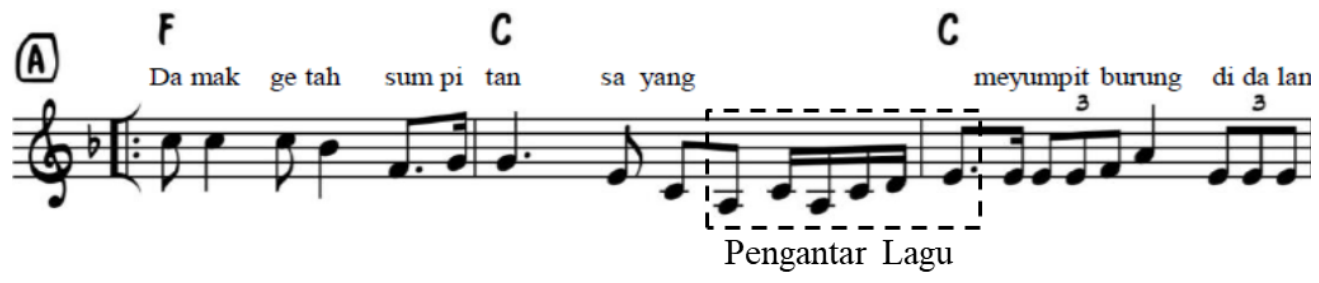

Rajah 10: Melodi pengantar dari lagu Damak nyanyian Siti Nurhaliza (SuriaRecordsSRC, 2013) 
Berdasarkan Rajah 7, 8, 9 dan 10 di atas, jelas menunjukkan penggunaan pengantar lagu yang konsisten. Jika pengantar lagu ini tidak dimainkan, penyanyi tidak boleh teruskan menyanyi kerana pengantar lagu ini berfungsi sebagai panduan mereka untuk memulakan nyanyian pada bahagian berikutnya, kenyataan ini disokong oleh Abu Bakar (2014), Arshad (2015), Ahmed dan Kechot (2015), Zuarman Ahmad (temu bual peribadi, Mac 14, 2016) serta Isyak (2018). Contohnya seperti dalam baris ketiga pada Rajah 9, pada bit pertama, iaitu not B, yang juga merupakan not untuk melodi vokal. Begitu juga pada Rajah 10, bit pertama pada baris ketiga ialah not E dan melodi vokal juga memulakan nyanyai dengan not yang sama. Keadaan ini yang dimaksudkan dengan Rizaldi (2010) yang menyatakan kepentingan pengantar lagu ini berfungsi menghubungkan melodi lagu Melayu Asli. Daripada pemahaman teori muzik barat, pengantar lagu ini juga boleh dilihat sebagai satu rangkai melodi tetap yang berfungsi sebagai counter-melody (Mohd Khair Abdul Latif, temu bual peribadi, Febuari 26, 2019; Ramlan Mohd Imam, temu bual peribadi, Febuari 18, 2019). Ini berikutan fungsi pengantar lagu sinonim dengan fungsi counter-melody, merupakan satu melodi yang melengkapkan melodi utama dalam sesebuah lagu (Nick, 2018).

\section{Gabungan Elemen Masa dan Nada (Tekstur dan Struktur Muzik)}

Secara umumnya, tekstur dalam muzik merujuk pada lapisan bunyi yang terhasil dari tempo, melodi, harmoni, rentak dan timbre (Arshad, 2015; Mohd Rosly, 2018; Chase, 2020).Tekstur muzik dalam lagu Melayu Asli berbentuk heterofoni, iaitu penyanyi dan pemuzik memainkan melodi serentak dengan variasi mereka yang tersendiri (Feezell, 2011; Arshad, 2015; Mohd Rosly, 2018).

Menurut Rizaldi (2010), pada awalnya pemuzik lagu Melayu Asli tidak menggunakan terminologi muzik seperti intro, interlud mahupun koda. Ini kerana struktur lagu Melayu Asli terbentuk berdasarkan struktur pantun (Abu Bakar, 2010; Ahmed \& Kechot, 2015; Arshad, 2015; Isyak, 2018; Mohd Rosly, 2018). Struktur lagu Melayu Asli secara keseluruhannya berbentuk $A B$ atau dikenali sebagai $A B$ form dalam bahasa Inggeris, merangkumi dua bahagian, A dan B (Rizaldi, 2010; Arshad, 2015; Ahmed \& Kechot, 2015; Mohd Rosly, 2018). Jika melodi dinyanyikan secara vokal, bahagian A merupakan melodi lirik pembayang pantun dan bahagian B pula berkisarkan tentang maksud pantun (Arshad, 2015). Jika diterjermahkan struktur AB dalam bentuk grafik, berikut merupakan contoh transkripsi lirik dari diskografi:

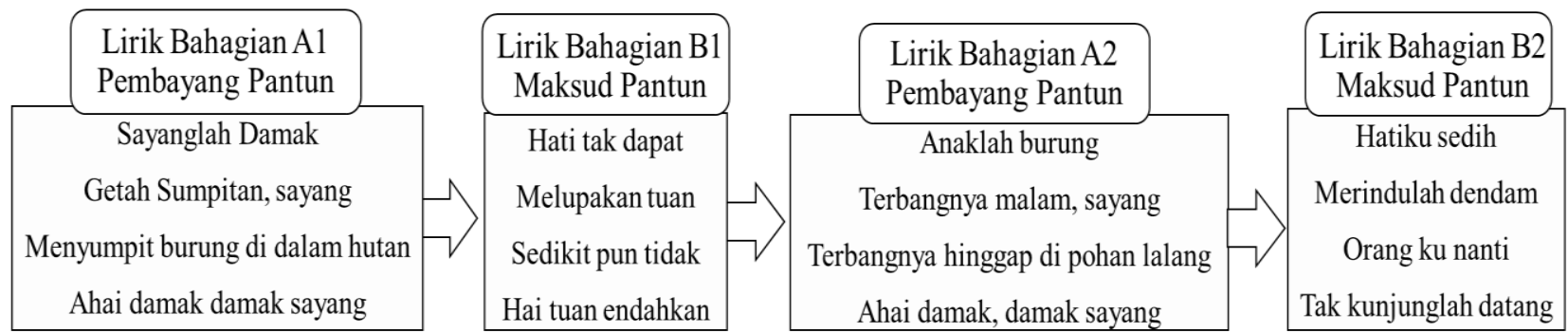

Rajah 11: Struktur lirik lagu Melayu Asli Damak nyanyian Siti Nurhaliza (SuriaRecordsSRC, 2013)

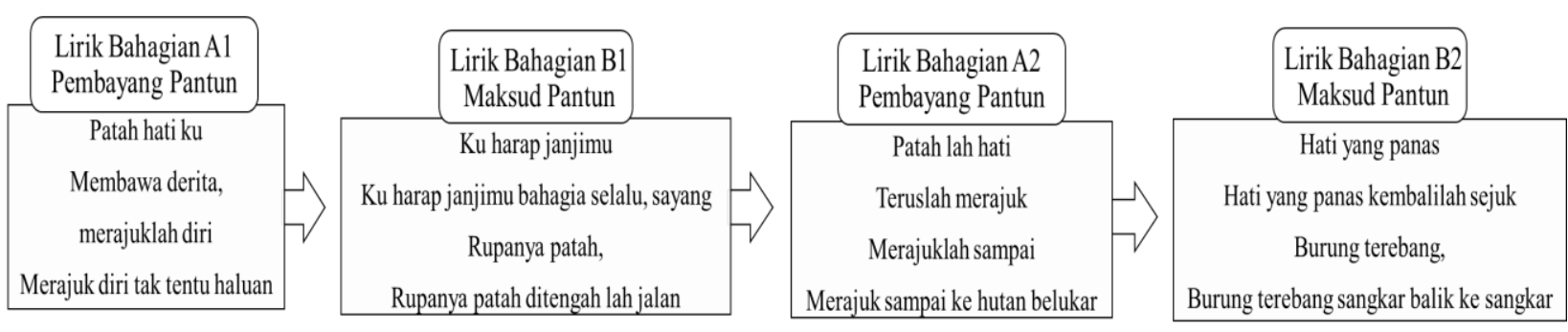

Rajah 12: Struktur lirik lagu Melayu Patah Hati nyanyian Siti Nurhaliza (SuriaRecordsSRC, 2013)

Struktur lagu Melayu Asli juga dikenali sebagai bentuk strofik, iaitu rangkap pantun atau melodi lagu yang berulang-ulang (Arshad, 2015; Mohd Rosly, 2018). Struktur lagu Melayu Asli dikenali sebagai struktur A-B A-B (Ismail Ahmed, temu bual peribadi, April 30, 2020). Disebabkan pola irama melodi yang berulang ini, membolehkan penyanyi mahupun pemuzik iringan bebas mengimprovisasi alunan melodi 
mengikut kreativiti mereka yang tersendiri (Arshad, 2015). Rizaldi (2010) ada menyatakan bahawa, disebabkan struktur lagu Melayu Asli ini asalnya hanya dalam bentuk AB, para pemuzik ketika itu mengubah semula struktur lagu Melayu Asli dengan penambahan bahagian intro, interlud dan koda dengan melodi yang tidak berlanggaran dengan melodi asas. Ismail Ahmed juga menambah bahawa intro dalam lagu Melayu ini unik dan dimainkan pada awal baris muzik, serta setiap lagu diciptakan khusus dengan intro yang tertentu menentukan sesebuah lagu (temu bual peribadi, April 30, 2020). Kenyataan ini juga bermaksud, terdapat nada-nada tertentu yang berhubung kait dengan melodi nyanyian atau melodi asas (Abu Bakar, 2014; Ahmed \& Kechot, 2015; Arshad, 2015). Oleh kerana itu, penyelidik lepas seperti Arshad (2015) dan Abu Bakar (2014) menyatakan, pemuzik mahupun penyanyi perlu menghafal melodi bahagian buka lagu (Jadual 2). Berikut dijelaskan lebih terperinci maksud terdapat not-not yang berkaitan antara melodi nyanyian dan buka lagu yang dinyatakan pada Rajah 13, 14 dan 15 di bawah:

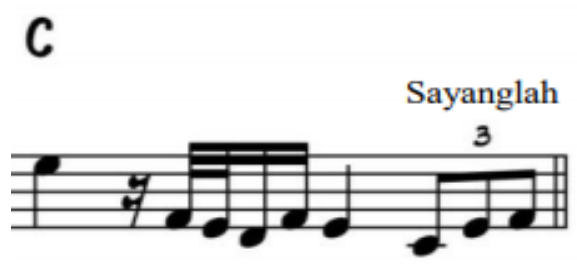

Rajah 13: Keratan melodi Damak nyanyian Sudirman (Mrcupan, 2009)

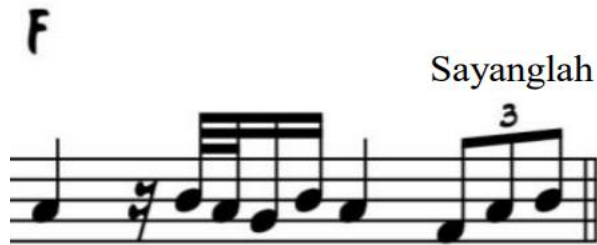

Rajah 14: Keratan melodi Damak nyanyian Siti Nurhaliza (SuriaRecordsSRC, 2013)

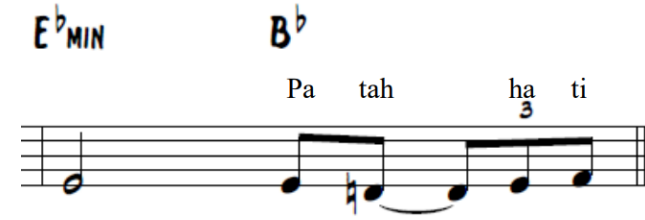

Rajah 15: Keratan melodi Patah Hati nyanyian Siti Nurhaliza (SuriaRecordsSRC, 2013)

Merujuk pada Rajah 13, not F dan E yang dimainkan oleh muzik pengiring juga terdapat pada not melodi nyanyian. Rajah 14 juga menunjukkan pola yang sama, iaitu persamaan not $\mathrm{A}$ dan $\mathrm{B} b$ yang terdapat dalam melodi pengantar lagu dan melodi nyanyian. Dalam Rajah 15 pula, contoh dari lagu Patah Hati juga menunjukkan persamaan pada not $\mathrm{Eb}$ antara muzik pengiring dan melodi nyanyian. Selain daripada seimbang, melodi instrumental dan vokal ini saling memerlukan serta antara keduanya saling tidak terpisah (Rizaldi, 2010; Arshad, 2015; Zuarman Ahmad, temu bual peribadi, Mac 14, 2016). Persamaan not ini juga bertujuan untuk membantu penyanyi memahami pic yang tepat agar nyanyian melodi tidak sumbang. Intro ini penting sebagai indikator untuk penyanyi bersedia untuk menyanyi mengikut pic yang digunakan. Intro dalam lagu Melayu dikatakan unik kerana diciptakan khusus dalam menentukan sesebuah tajuk lagu (Ismail Ahmed, temu bual peribadi, April 30, 2020).

\section{Rumusan}

Hasil daripada analisis dalam literatur lagu Melayu Asli ini, dapat dirumuskan ciri-ciri umum lagu Melayu Asli yang boleh dilihat dari aspek struktur asal komposisi lagu Melayu Asli ini berasaskan daripada struktur $\mathrm{AB}$, kemudian ditambah dengan bahagian intro, interlud dan outro. Rentak asli atau senandung ini yang dimainkan pula dalam tempo yang perlahan, sekitar 55 sehingga 75 bit per minit. Akhir sekali, ciri yang 
harus ada dalam komposisi lagu Melayu Asli ialah, melodi Pengantar lagu, satu rangkai melodi pendek yang dimainkan sebelum atau selepas melodi utama atau melodi nyanyian. Ciri pengantar lagu ini juga seperti fungsi counter-melody yang melengkapi melodi utama dalam lagu Melayu Asli.

Walaupun penulisan ini terhad dengan limitasi dua transkripsi diskografi repertoir popular lagu Melayu Asli seperti Damak (Silahudin, 2010, 2013; Ahmed \& Kechot, 2015; Arshad, 2015; Mohd Rosly, 2018) dan Patah Hati (Silahudin, 2010 \& 2013; Ahmed \& Kechot, 2015; Arshad, 2015; Isyak, 2018). Diharapkan penulisan artikel ini dapat membantu penyelidik, pelajar, pengamal dan penggubal dasar memahami, mengenal pasti dan mengkritik literatur yang sedia ada, agar pengetahuan dan kefahaman kita terhadap sesuatu topik itu dapat diperhalusi dan dipertingkatkan (Clark \& Creswell, 2015), khususnya melibatkan lagu Melayu Asli.

Penulis juga ingin mencadangkan agar pengkaji akan datang boleh melakukan kajian yang lebih berfokuskan pada biografi komposer mahupun pemuzik lagu Melayu Asli yang masih hidup. Melalui kajian biografi yang berfokuskan elemen muzik seperti ini, kita dapat memahami mendalami ilmu dalam lagu Melayu Asli dengan lebih eksplisit. Selain daripada kajian biografi muzikal, penyelidik akan datang juga boleh mengkaji lagu Melayu Asli khususnya melibatan istilah-istilah dalam persembahan lagu Melayu Asli yang masih belum diterokai, mengkaji struktur lagu-lagu Melayu Asli yang mungkin terdapat perbezaan.

Kajian berkenaan lagu Melayu Asli ini diharap tidak hanya dapat memupuk minat dalam kalangan cendekiawan, malahan dapat mendorong pemuzik, pengamal, aktivis mahupun pelajar dalam memelihara khazanah muzik tradisional tempatan ini agar terus terpelihara dan berkembang meniti arus perdana ini.

\section{Rujukan}

Abdullah, A. (2015, September 11). Martabat lagu Melayu Asli di DFP. Harian Metro. https://www.hmetro.com.my/node/76798

Abu Bakar, N. A. (2014). Modul asas pengajaran dan pembelajaran nyanyian lagu Melayu Asli. [Master's thesis, Universiti Pendidikan Sultan Idris]. Repository Khazanah Melayu. http://melayu.library.uitm.edu.my/1743/1/MODUL\%20ASAS\%20PENGAJARAN\%20DAN\%20PEMBEL AJARAN\%20NYANYIAN\%20LAGU\%20MELAYU\%20ASLI.pdf

Ahmed, I. \& Kechot, A. S. (2015). Lagu Melayu asli: Unsur sinkretisme dalam instrumentasi persembahan. Jurnal Melayu, 14(2), 307-327. http://ejournals.ukm.my/jmelayu/article/download/11451/3712

Alimi, K. F. \& Kassin, T. A. (2018). Proses penengahan vokal rendah/a/dalam lagu Melayu Asli. Jurnal Linguistik, 22(1), 49-61. https://ejurnal.plm.org.my/index.php/jurnallinguistik/article/download/47/39

Arshad, S. F. (2015). Manual asas permainan lagu Melayu asli secara instrumental. (Unpublished master's thesis). Akademi Seni Budaya dan Warisan Kebangsaan, Kuala Lumpur, Malaysia.

Ayderova, V., Wong, H. Y. @ C., Augustine, C., \& Arshad, S. F. (2020). Learning ornament signs through transcriptions of Malaysian folk songs in an applied music course. International Journal of Academic Research in Business and Social Sciences, 10(5), 381-393. http://dx.doi.org/10.6007/IJARBSS/v10-i5/7209

Azrael667, (2014, November 17). Re: 8/4 time signature. Ultimate-Guitar Forum. https://www.ultimateguitar.com/forum/showthread.php?t=1661815

Bahasuan, M. A. (2003). The Malay culture and its evolution. http://www.srimahligai.com/articles/malay_music_culture.htm

Berklee Online. (2018, April 5). What is timbre? Beginner, music production, berklee online [Video]. YouTube. https://www.youtube.com/watch?v=AjJLAcDb_MU

BERNAMA. (2015, September 21). Memartabat lagu Melayu asli ke persada antarabangsa. JKKN. http://www.jkkn.gov.my/en/memartabat-lagu-melayu-asli-ke-persada-antarabangsa

Chase, S. (2020, Oktober 17). What is texture in music? A complete guide. Hello Music Theory. https://hellomusictheory.com/learn/texture/

Clark, V. L. P., \& Creswell, J. W. (2015). Understanding research: A consumer's guide. Pearson Higher Ed.

Creswell, J. W. \& Creswell, J. D. (2018). Research design: Qualitative, quantitative, and mixed methods approaches ( $5^{\text {th }}$ ed.). Sage Publications.

Creswell, J. W. \& Poth, C. N. (2018). Qualitative inquiry \& research design: Choosing among five approaches (4 ${ }^{\text {th }}$ ed.). Sage Publication.

Creswell, J. W. (2013). Research design: Qualitative, quantitative, and mixed methods approaches (4 ${ }^{\text {th }}$ ed.). Sage Publications.

Creswell, J. W. (2016). 30 essential skills for the qualitative researcher. Sage Publication.

Dewan Bahasa dan Pustaka (n.d.). Tempo. Kamus Dewan Bahasa dan Pustaka. http://prpm.dbp.gov.my/caril ?keyword=tempo

Feezell, M. (2011). Music theory fundamentals: High-yield music theory (Vol. 1). http://kutubxona.adu.uz/kutubxona/19musictheoryfundamentalspdf.pdf 
Hashim, M. N. (2012). Variation of Malay Asli music: There is no 'right or wrong'. In Loo, F. Y., Hashim, M. N. \& Loo, F. C. (Eds.), Essays on issues in music and its function: UM book Series on Research in Musicology 4. (pp. 1-17). Lambert Academic Publishing.

https://www.researchgate.net/profile/Zaharul_Saidon2/publication/294088667_Developing_Malaysian_Hig h_School_Marching_Bands_Issues_Challenges_and_Strategies/links/56bdf22e08ae44da37f88393.pdf\#pag $\mathrm{e}=16$

Irving, D. R. (2014) Hybridity and harmony: Nineteenth-century British discourse on syncretism and intercultural compatibility in Malay music. Indonesia and the Malay World, 42(123), 197-221. https://doi.org/10.1080/13639811.2014.912408

Isyak, F. N. (2018) Oral transmission and stylistic issues in Malay Asli Song in Johor. [Master's thesis, Universiti Malaya]. University of Malaya Students Repository. http://studentsrepo.um.edu.my/8949/2/NIDZAM_FINAL_20APRIL2018.pdf

Jazz_rock_feel. (2014, November 17). Re: 8/4 time signature. Ultimate-guitar forum. https://www.ultimateguitar.com/forum/showthread.php?t=1661815

Karim, M. K. (2016). Inspirasi penciptaan komposisi muzik Ghamuhyi: Sebuah karya muzik baharu bersumber dari muzik tradisional ghazal Melayu Johor. Malaysian Journal of Music, 5(1), 74-91. https://ejournal.upsi.edu.my/index.php/MJM/article/view/816/552

Kostka, S. M., Payne, D., Almen, B. (2012). Tonal harmony with introduction to twentieth-century music ( $7^{\text {th }}$ ed.). McGraw-Hill Higher Education.

Manoharan, P., Sulong, M. A., Raja Adnan, R. A. N. (2009). HBMS4203 Muzik Tradisional. Open Universiti Malaysia.

http://s206.oum.edu.my/pluginfile.php/6163/course/overviewfiles/04\%20HBMS4203\%20CG.pdf?forcedow nload $=1$

Matusky, P. (1985). An introduction to the major instruments and forms of traditional Malay music. Asian Music, 16(2), 121-182. https://doi.org/10.2307/833774

Matusky, P., \& Tan, S. B. (2017). The music of Malaysia: The classical, folk and syncretic traditions. Taylor \& Francis.

Mazlan, C. A. N. \& Abdullah, M. H. (2020). Utilizing pragmatism principles in learning jazz guitar reharmonization technique using Malay Asli song. International Journal of Applied and Creative Arts, 3(1), 54-66. https://doi.org/10.33736/ijaca.2188.2020

Mazlan, C. A. N. (2016). Perkembangan kord dalam improvisasi gitar. (Unpublished master's thesis). Universiti Pendidikan Sultan Idris, Perak, Malaysia.

Mohd Rosly, N. S. R. (2018). Kajian ornamentasi dalam muzik Melayu Asli: Permainan violin gaya Hamzah Dolmat. [Master's thesis, Universiti Malaya]. University of Malaya Students Repository. http://studentsrepo.um.edu.my/8607/3/NIK_SHAREENA_ROSNY_FULL_THESIS_FINAL.pdf

Mohd Shah, S. \& Masumi, M. A. (2016). Teaching traditional music in Malaysian schools: Considering the cultural context. International Journal of Learning and Teaching, 8(1), 69-76. https://doi.org/10.18844/ijlt.v8i1.511

Mohd Shah, S. (2013). Contextualizing the transmission of Malaysian traditional music. Procedia-Social and Behavioral Sciences, 93, 1000-1004. https://doi.org/10.1016/j.sbspro.2013.09.318

Mrcupan. (2009, Mac 3). Sudirman - Damak [Video]. YouTube. https://www.youtube.com/watch?v=YrYFcZhxZC0

Nick. (2018, Januari 25). A beginner's guide to counter-melodies. Medium.com. https://medium.com/@ NickEss/abeginners-guide-to-counter-melodies-ebc5ae8b10cd

Nicksword87. (2014, November 17). Re: 8/4 time signature. Ultimate-Guitar Forum. https://www.ultimateguitar.com/forum/showthread.php?t=1661815

Orduña-Malea, E., Martín-Martín, A., M. Ayllon, J. \& Delgado López-Cózar, E. (2014), The silent fading of an academic search engine: The case of Microsoft Academic Search. Online Information Review, 38(7), 936953. https://doi.org/10.1108/OIR-07-2014-0169

Peter. (2019, Mei 23). Re: Counting in 8 rather than 4/4. Stack Exchange. https://music.stackexchange.com/questions/85142/counting-in-8-rather-than-4-4

Pilhofer, M., \& Day, H. (2019). Music theory for dummies. John Wiley \& Sons.

Pillai, S. (2013). Syncretic cultural multivocality and the malaysian popular musical imagination. Kajian Malaysia: Journal of Malaysian Studies, 31(1), 1-18. http://web.usm.my/km/31(1)2013/KM\%2031(1)\%20ART\%201\%20(1-18).pdf

Ritawati, T. (2017). The original of Malay songs (OMS) as the symbolism of Malay cultural heritage. International Journal of Social Sciences, 49(1). 67-72. http://tijoss.com/49th\%20volume\%20tijoss/6.pdf

Rizaldi. (2010, Ogos 26). Melakukan perubahan tanpa merusak tradisi dalam konteks aransemen musik Melayu. Blogspot. http://rizaldiisipadangpanjang.blogspot.com/2010/08/melakukan-perubahan-tanpa-merusak.html

Santai Minda. (2012, November 12). Irama Tradisional - Damak (Asli) 1080p [Video]. YouTube. https://www.youtube.com/watch?v=V4tVZOWc2T0

Schmidt-Jones, C. (2012). The basic elements of music. Connexions. http://www.uilis.unsyiah.ac.id/oer/files/original/37f9c950bbcc53eb2778fad5929a99c7.pdf 
Silahudin, S. (2010). Nyanyian Melayu Asli sebagai warisan manifestasi kesenian Melayu: Tumpuan pandangan pemikir-pemikir budaya. In Ahmad, M. N. \& Hamidon, N. A. (Eds.) Monograf: Jabatan Kesenian Melayu 2010. Akademi Pengajian Melayu, Universiti Malaya.

https://www.academia.edu/3657136/Nyanyian_Melayu_Asli_Sebagai_Warisan_Manifestasi_Kesenian_Mel ayu_Tumpuan_Pandangan_Pemikir-Pemikir_Budaya

Silahudin, S. (2013). Nyanyian Melayu Asli: Vokalisasi serta peranan korda dan larinks. Prosiding Persidangan Kearifan Tempatan: Pengalamanan Nusantara (Jilid 2), 2-37. https://www.academia.edu/3792386/Nyanyian_Melayu_Asli_Vokalisasi_Serta_Peranan_Korda_Vokal_dan _Larinks

SuriaRecordsSRC. (2013, Oktober 7). Siti Nurhaliza - Damak (Official Video - HD) [Video]. YouTube. https://www.youtube.com/watch?v=wlBpyvqxDsQ

SuriaRecordsSRC. (2013, Oktober 7). Siti Nurhaliza - Patah (Official Video - HD) [Video]. YouTube. https://www.youtube.com/watch?v=r1_3TW5kJwc

The Editors of Encyclopaedia Britannica. (June 27, 2013). Metre. Encyclopaedia Britannica. https://www.britannica.com/art/metre-music

Tim. (2020, Mei 17). Re: Is 8/4 signature a thing? Music: Practice \& theory stack exchange. https://music.stackexchange.com/questions/99706/is-8-4-time-signature-a-thing\#comment172078_99706

Wright, C. [Chris Wright]. (2016, Januari 28). What is Tone Color? (Timbre) [Video]. YouTube. https://www.youtube.com/watch?v=5tGEDgkZlC8

Za'Ba, N., Jamil, N., Salleh, S. S., Abdul Rahman, N. (2011). Investigating ornamentation in Malay traditional, asli music. http://www.wseas.us/e-library/conferences/2011/Montreux/COMICICBIO/COMICICBIO-06.pdf 